\title{
Customers' Perceptions on ESKOM's Pre-Paid Billing System and the Effects on Their Satisfaction and Trust
}

\author{
Richard Chinomona \\ University of the Witwatersrand, School of Economics and Business Sciences, South Africa \\ Maxwell Sandada
}

University of Zimbabwe, Graduate School of Business, Zimbabwe

\section{Doi:10.5901/mjss.2014.v5n9p119}

\section{Abstract}

\begin{abstract}
Despite the increasing awareness of the paramount importance of customer satisfaction and trust in the context of large firms, research efforts focused on the investigation of the role of electricity pre-paid system performance on customer satisfaction and trust have largely remained scant, particularly in developing countries of Southern Africa. Therefore, the primary objective of this study is to fill this void. Three research hypotheses are posited and a sample data of 151 collected from ESKOM company' electricity pre-paid system customer is used to empirically test the hypotheses. The results of this study show that, the performance of the ESKOM prepaid billing system positively influences the customers' satisfaction and trust in a significant way. Managerial implications of the findings are discussed and limitations and future research directions are indicated.
\end{abstract}

Keywords: Pre-paid system; Customer trust; Customer satisfaction

\section{Introduction}

The electricity supply system in South Africa has experienced unprecedented challenges and transformations in recent years. The ever growing demand for electricity has been necessitated by the ever-growing number of industries, mining, commercial, agriculture, residential and redistributors in the country. It is expected that electricity demand will keep on increasing and hence put the power utility company, Eskom under serious pressure. Improving the service quality is therefore a priority for the organisation to satisfy and gain customer trust (Andaleeb, 2001). In an effort to improve its service, Eskom introduced the pre-paying billing system which requires customers to pay the bills before they consume the service.

However, little is known about the perceptions of customers on the performance of the pre-paid system and its effect of their satisfaction and trust. Empirical work suggests that organisations that provide quality service are better placed to satisfy customers (Naidu, 2009; Segoro, 2013) and gain customer trust (Irani, Fathollahzdeh and Alavi, 2012; Gill, Flaschner and Shacher, 2006). Andaleeb (2001) recommends that customer satisfaction is an important component in designing service provision in developing countries. Karjaluoto, Jayawardhena, Leppaniemi and Pinlstrom (2010) also show that quality service provision leads to customer trust.

This study seeks to develop a conceptual model that shows the influence of perceived service quality on customer satisfaction and customer trust. Evaluating the impact of perceived service quality on customer satisfaction and trust will provide practical guidelines for Eskom management on how to provide service quality of their prepaid system in order to satisfy customers and ultimately customer trust. Such guidelines are necessary as they assist Eskom to improve its electricity supply service.

The contribution of this study to Eskom and other power utility organisations is two-fold. First, it develops a conceptual model that incorporates the variables discussed above. Lastly, the study develops hypotheses, collects data and then tests the hypotheses to establish the effect of perceived quality on customer satisfaction and trust.

The rest of the paper is arranged as follows: A theoretical review, the theoretical framework and hypotheses will firstly be presented. Thereafter the methodology, data analysis and conclusions are discussed. The final section presents the managerial implications, limitations and recommendations for future research. 


\subsection{Perceived service quality}

A general agreement exists among academics and practitioners about the importance of customer service to the success of organisations. According to Seto-Pamires (2012), perceived service quality refers to the ability of a service provider to provide a service that meets or exceed customer expectations. For Chang and Horng (2010), perceived service quality involves customer experiences whereby customers are willing to pay for the service provided as a result of having their psychic needs satisfied. This is consistent with Akter, D'Ambra and Ray (2013) who posit that the service provider's performance is judged as superior if it meets the preconceived expectations of customers. This demonstrates that the ability to provide service quality has become a necessary condition for organisational success (Calabrese \& Scoglio, 2012). The importance of service quality is further demonstrated by other scholars such as $\mathrm{Hu}$, Kantampully and Juwaheer (2009) who describe service quality as an uncompromisable component of service promise. Due to its influence on customer behavioural intentions, the authors recommend that in order to survive and succeed in today's competitive conditions, it is imperative that service providers provide quality service. A widely used framework to evaluate service quality is the SERQUAL framework developed by Parasuraman, Zeithaml and Berry (1988). According to Parasuraman et al. (1988), the SERQUAL framework is based on the comparison between customer expectations and perceived performance standard by the service provider based on five dimensions (tangibles, reliability, responsiveness, assurance, responsiveness and empathy). It means that to meet customer expectations, the service should be relied on, responsive to customer needs, assure customers that their needs will be satisfied, feel for customers, and have attractive physical attributes. Seth, Deshmukh and Vrant (2005) identified three components of service quality namely technical quality, functional quality and image of the service provider. Technical quality is the actual service provided to customers, functional quality shows how the service is provided and the perceived image is the reputation as a result of its relation with customers (Seth et al., 2005).

\subsection{Customer satisfaction}

According to Seto-Pamies (2012), customer satisfaction occurs when the service provider positively confirms to customer expectations. Javadein, Khanlari and Estiri (2008) view customer satisfaction as the customers' feelings that their needs and expectations are fulfilled based certain quality dimensions. Choi and Sheel's (2012) definition include the output and process aspects of customer satisfaction. The output definition views customer satisfaction as a cognitive or mental state in which consumers feel that they have been adequately or inadequately compensated. Regarding the process, customer satisfaction occurs when customer experience matches or exceeds the expectations. Echoing the same sentiments, Brunner, Stocklin and Opwis (2008) maintain that after the service has been performed, customers compare the performance against their expectations. Whereas disconfirmation (customer dissatisfaction) happens when there is a discrepancy between expectations and performance, confirmation (customer satisfaction) occurs when performance equals or exceeds expectations. The authors proceed to state that customer satisfaction can be cumulative or transaction-specific. While cumulative satisfaction indicates customer's positive experiences with the service provider, transaction-specific satisfaction is customer's satisfaction with a single encounter. In order to satisfy consumers, retailers need to understand the motivations for shopping because customers gain satisfaction from diverse shopping aspects (Huddleston, Whipple, Mattick \& Lee, 2009).Some of the motivations for consumer shopping mentioned by Huddleston et al. (2009) are task oriented while others are activity oriented and they include shopping to divert from daily routine, to learn more about trends and new products, to enjoyment bargaining. Consumer evaluation therefore is crucial customer satisfaction because service providers are able to identify customer expectations (Choi \&Sheel, 2012).

\subsection{Customer trust}

Customer trust refers to the willingness of customers to rely on the service provider due to a belief in the service provider's honest, competence, benevolence and reliability in providing a service that satisfies their needs (Naidu, 2009; Chen, 2012). According to dos Santos and Fernandes (2008), customer trust occurs in two ways, namely trust in employees and trust in the service provider. While the former is based on the behaviour of employees, the latter is trust in the policies and procedures of the service provider that affect its relationship with customers. Trust in service provision is of paramount importance because it reduces customer perceived risk, customers are able to manage risks and it simplifies customer's decision to choose (Seto-Pamires, 2012). Chang (2012) suggests that customer trust can either be affective (customer belief that the service provider will keep promises) and cognitive (customers believe that the service provider aims to satisfy their needs at a profit). Customers develop trust in service providers if they have confidence that 
the product or service being provided benefits them (Dabholkar \& Sheng (2012)). Therefore service providers should be competent and dependable in meeting the customer expectations in order to create customer trust.

\section{Conceptual Model and Hypothesis Development}

Drawing from the extant literature from customer service, customer satisfaction and trust aforementioned, a conceptual model is developed in Figure 1. The model consists of three constructs, that is, one predictor-perceived service quality, and two outcome variables- customer satisfaction and customer trust. While customer satisfaction is an outcome, it is also treated as a mediating factor in the model. The relationship between the constructs is that Eskom's perceived service performance has a direct influence on both customer satisfaction and trust. On the other hand the perceived service quality by Eskom influences customer trust through customer satisfaction because the quality service provided positively influences customer satisfaction which will lead to customer trust. The next sections provide detailed explanations of the associations between these constructs and the hypotheses are developed hereafter.

Figure 1: The Conceptual Model

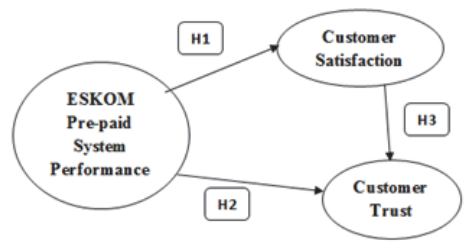

\subsection{Perceived service quality and customer satisfaction}

The quality-satisfaction relationship is a subject that has not been agreed upon by academics. While some scholars argue that the relationship between the two constructs is reciprocal (Deng, Lu, Wei \& Zhang, 2010), others regard customer satisfaction as an antecedent to service quality (Naidu, 2009; Segoro, 2013; Elliot, Li \& Choi, 2013). This study argues that customers derive satisfaction from the quality of service provided, therefore perceived service quality precedes customer satisfaction. Seto-Pamies's (2012) demonstrates that the five service quality dimensions (tangibility, reliability, responsiveness, assurance and empathy) had a positive and significant impact on customer satisfaction. Hu, Kandampully and Juwaheers' (2009) study found that delivering high quality service results in high levels of customer satisfaction. The results are buttressed by the findings of a study of higher education by Dado, Petrovicova, Cuzovic and Rajc (2012) which report service quality as a precursor to customer satisfaction. Similarly, in the context of sport services industry, Javadein et al. (2008) found that both technical and functional quality variables have a positive effect on customer satisfaction. According to Akter et al.'s (2013) study of service quality of the health service in Australia, perceived quality was found to be effective in predicting customer satisfaction. In the same vein, Elliot et al. (2013) report a positive relationship between perceived service quality and customer satisfaction. Significant associations were also found between dimensions of service quality and patient satisfaction in a study of hospitals in Bangladesh by Andaleeb (2001). This is consistent with the study by Segoro (2013) which found that dimensions namely the call quality, price structure, mobile devices, value added services and customer support, exhibited positive direct influence on customer satisfaction. Other scholars such as Choi, Cho, Lee, Lee and Kim (2004) and Abu-El Samen and Akroush (2012) also show evidence that service quality is an antecedent to customer satisfaction. The study therefore proposes the following hypothesis:

\section{H1: Perceived service quality has a positive influence on customer satisfaction}

\subsection{Perceived service quality and customer trust}

According to a study conducted on a health delivery environment by Naidu (2009), the provision of quality health service patients enhanced their trust in the hospital. This indicates that if customers perceive a quality service is provided to them, their trust in the service provider strengthens. Similar results are also reported in a study of service quality of virtual travel community environment by Elliot et al. (2013). Gill et al.(2006) found that the customer's trust was enhanced by the service provider's empathy, reliability, politeness, and customisation. Karjaluoto, Jayawardhena, Leppaniemi and 
Pinlstrom (2010) studied the influence of customer value and trust in the wireless telecommunications industry and found that the service that provides functional, monetary, social and emotional value, significantly impacts on customer trust. Irani et al. (2012) also examined the service quality among Iranian banks and found evidence showing that both technical and functional aspects of service provision by the banks positively influenced customer trust. This shows that if customers perceive the service performance to be superior, they develop trust in the service provider. The following hypothesis is postulated:

H2: Perceived service quality has a positive effect on customer trust

\subsection{Customer satisfaction and customer trust}

Chen (2012) posits that positive experiences that satisfy customers are more likely to enhance customer trust and a longtime relationships with the service provider. This notion is supported by Dabholkar and Sheng (2012) in their study of the effect of customer satisfaction on customer trust within the online business transactions environment. This means that encounters that are customer satisfying positively impact on customer trusting. The predictive power of customer satisfaction on customer trust is supported by Ou and $\operatorname{Sin}(2003)$ whose study of service provision by e-retailers found service quality components namely privacy and security aspects to be important determinants of e-retailing customers' trust. This further demonstrates the effect of customer satisfaction on customer trust. In addition, Olaru, Purchase and Peterson (2008) assert that the satisfying encounters experienced by customers lead customer to trust the service provider. Customer trust in the service provider develops as a result of pleasing experiences (Boshoff \& du Plessis, 2009). The study therefore hypothesises that:

\section{H3: High levels of customer satisfaction have a positive effect of customer trust}

\section{Research Methodology}

\subsection{Sample and data collection}

The target population for the study was South African ESKOM electricity pre-paid system customers or clients in Gauteng Province of South Africa. Students from the Vaal University of Technology were recruited as research assistants to distribute and collect the questionnaires. Of the total of 170 questionnaires distributed, 151 usable questionnaires were retrieved for the final data analysis, representing a response rate of 89 per cent. Respondents were asked to complete the entire questionnaire, guided by the research assistants where it was necessary.

\subsection{Measurement Instrument and Questionnaire Design}

Research scales were operationalised on the basis of previous work. Proper modifications were made in order to fit the current research context and purpose. "Pre-paid system performance" measure used five-item scale adapted from Tseng and Huang (2011). "Customer satisfaction" and "Customer trust" were all measured using a three-item scale all adapted from Liu, Guo and Lee (2011). All the measurement items were measured on a five-point Likert-type scales that was anchored by $1=$ strongly disagree to $5=$ strongly agree to express the degree of agreement. Individual scale items are listed in Appendix 1.

\subsection{Respondent Profile}

Table 1 presents the description of the participants. The respondents were asked to report their demographic information, including gender, age, marital status and education. The respondents were predominantly females (57.6\%). The median age group of the respondent was that of less than 30 years (54.3\%). $57 \%$ of the respondents were single. About $71 \%$ of the respondents had either high school (43.7\%) or university level of education (27.2\%) and the remainder had primary school (19.9) or postgraduate level of education (0.09\%).

\section{Data Analysis}

\subsection{Structural Equation Modelling Approach}

In order to statistically analyze the measurement and structural models, this study used Smart PLS software for Structural 
Equation Modeling (SEM) technique (Ringle, Wende \& Will 2005). In SEM, the measurement model refers to the linkages between the latent variables and their manifest variables and the structural model captures the hypothesized causal relationships among the research constructs (Chin \& Newsted, 1999). Unlike AMOS and LISREL which are covariancebased approaches, Smart PLS is a regression based technique that originates from path analysis. Smart PLS has emerged as a powerful approach to study causal models involving multiple constructs with multiple indicators (Chinomona \& Surujal, 2012). Smart PLS - a component-based method, has an ability to model latent constructs that are uncontaminated by measurement error under conditions of non-normality. It has the ability to handle complex predictive models in small-to-medium sample sizes. Since the current study sample size is relatively small (150) Smart PLS was found more appropriate and befitting the purpose of the current study. In this respect, Bootstrapping resampling method was used to test the statistical significance of the relationships. This procedure entailed generating 200 sub-samples of cases randomly selected, with replacement, from the original data. Below is Table 2, presenting evidence on the reliability and validity of the measurement model.

\subsection{Measurement Model}

To ensure convergent validity, the researcher checked if items loaded on their respective (a priori) constructs with loadings greater than 0.6 , while discriminant validity was checked by ensuring that there was no significant inter-research variables cross-loadings (Chin, 1998). As can be seen (Table 2), all items have loadings greater than 0.6 (i.e. ranging from 0.677 to 0.876 ), with no cross-loadings greater than 0.898 , while t-statistics derived from bootstrapping (200 resamples) suggest all loadings are significant at pb0.001. As such, this confirms that all the measurement items converged well on their respective constructs and therefore are acceptable measures.

Table 2: Accuracy Analysis Statistics

\begin{tabular}{|c|c|c|c|c|c|c|c|c|}
\hline \multicolumn{2}{|c|}{$\begin{array}{l}\text { Research } \\
\text { Construct }\end{array}$} & $\begin{array}{c}\text { LV Index } \\
\text { Value }\end{array}$ & $\begin{array}{l}\text { R-Squared } \\
\text { Value }\end{array}$ & $\begin{array}{c}\text { Cronbach's } \alpha \\
\text { value }\end{array}$ & $\begin{array}{c}\text { C.R. } \\
\text { Value }\end{array}$ & $\begin{array}{c}\text { AVE } \\
\text { Value }\end{array}$ & Communality & $\begin{array}{l}\text { Factor } \\
\text { Loading }\end{array}$ \\
\hline \multirow{5}{*}{ EPS } & EPS1 & \multirow{5}{*}{3.9199} & \multirow{5}{*}{0.0000} & \multirow{5}{*}{0.6984} & \multirow{5}{*}{0.8046} & \multirow{5}{*}{0.4519} & \multirow{5}{*}{0.4519} & 0.681 \\
\hline & EPS2 & & & & & & & 0.698 \\
\hline & EPS3 & & & & & & & 0.641 \\
\hline & EPS4 & & & & & & & 0.647 \\
\hline & EPS5 & & & & & & & 0.692 \\
\hline \multirow{3}{*}{ CS } & CS1 & \multirow{3}{*}{3.9491} & \multirow{3}{*}{0.2044} & \multirow{3}{*}{0.4826} & \multirow{3}{*}{0.7356} & \multirow{3}{*}{0.4826} & \multirow{3}{*}{0.4826} & 0.629 \\
\hline & CS2 & & & & & & & 0.757 \\
\hline & CS3 & & & & & & & 0.693 \\
\hline \multirow{3}{*}{$\mathrm{CT}$} & CT1 & \multirow{3}{*}{4.0221} & \multirow{3}{*}{0.3722} & \multirow{3}{*}{0.4796} & \multirow{3}{*}{0.7338} & \multirow{3}{*}{0.4796} & \multirow{3}{*}{0.4796} & 0.733 \\
\hline & CT2 & & & & & & & 0.641 \\
\hline & CT3 & & & & & & & 0.701 \\
\hline
\end{tabular}

Note: EPS = Eskom Pre-paid System; CS = Customer Satisfaction; CT = Customer Trust

According to Chin (1998), research variables should have an average variance extracted (AVE) of more than 0.5 and a composite reliability of more than 0.7 (convergent validity), and inter-construct correlations should be less than the square-root of the AVE (discriminant validity). As can be seen (Table 2), all constructs exceed these criteria, with AVE and CR generally equal or greater than 0.5 and 0.8 , respectively. Furthermore, as indicated in Table 3 , the square-root of the lowest AVE is 0.82 and is greater than the highest inter-construct correlation value (0.0.808). All in all, these results confirm the existence of discriminant validity of the measurement used in this study.

Table 3: Correlations between Constructs

\begin{tabular}{|l|c|c|c|}
\hline \hline Research Constructs & EPS & CS & CT \\
\hline Eskom Pre-paid System (EPS) & 1.000 & & \\
\hline Customer Satisfaction (CS) & 0.452 & 1.000 & \\
\hline Customer Trust (CT) & 0.537 & 0.501 & 1.000 \\
\hline \hline
\end{tabular}

Note: EPS = Eskom Pre-paid System; CS = Customer Satisfaction; CT = Customer Trust 


\subsection{Path Model}

PLS also generates the path coefficients for the relationships modeled among the constructs. The significance of these coefficients was assessed using the bootstrap procedure (with 200 sub-samples) that provided the t-values for each path estimate. Figure 2 and Table 4 presents the results of the PLS analysis on the structural model along with the path estimates and t-values. Support for the study hypotheses, which are labeled on their corresponding paths in Figure 2, could be ascertained by examining the directionality (positive or negative) of the path coefficients and the significance of the t-values. The standardized path coefficients are expected to be at least 0.2 , and preferably greater than 0.3 (Chin 1998).

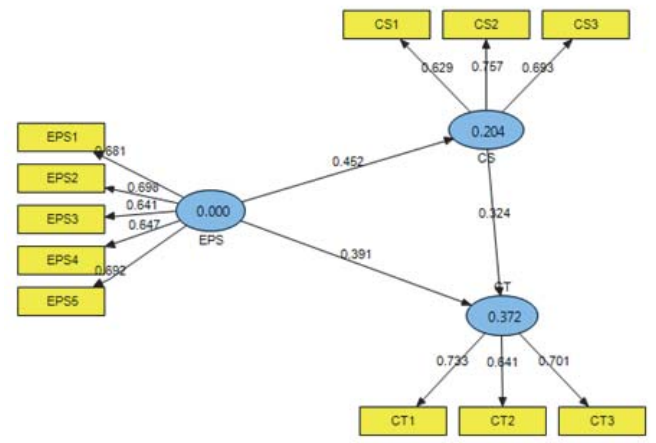

Note: EPS = Eskom Pre-paid System; CS = Customer Satisfaction; CT = Customer Trust

Figure 2: Measurement and Structural Model Results

The results provide support for the proposed positive relationships between the three relationships (i.e. $\mathrm{H} 1, \mathrm{H} 2$, and $\mathrm{H} 3$ ). Figure 2 and Table 4 provide the path coefficients for $\mathrm{H} 1, \mathrm{H} 2$, and $\mathrm{H} 3$ (i.e. $0.452,0.391$, and 0.324 respectively).

Table 4: Results of Structural Equation Model Analysis

\begin{tabular}{|l|c|c|c|c|}
\hline \hline \multicolumn{1}{|c|}{ Proposed Hypothesis Relationship } & Hypothesis & Path Coefficients & T-Statistics & Rejected / Supported \\
\hline Eskom Pre-paid System (EPS) $\rightarrow$ Customer Satisfaction (CS) & H1 & 0.452 & 3.477 & Supported \\
Eskom Pre-paid System (EPS) $\rightarrow$ Customer Trust (CT) & H2 & 0.391 & 5.735 & Supported \\
Customer Satisfaction (CS) $\rightarrow$ Customer Trust (CT) & H3 & $\mathbf{0 . 3 2 4}$ & 4.429 & Supported \\
\hline \hline
\end{tabular}

Note: EPS = Eskom Pre-paid System; CS = Customer Satisfaction; CT = Customer Trust

Overall, $\mathrm{R}^{2}$ for ERS (0.439) in Figure 2, indicate that the research model explains more than $43 \%$ of the variance in the endogenous variables. Following formulae provided by Tenenhaus, Vinzi, Chatelin \& Lauro, (2005), the global goodnessof-fit (GoF) statistic for the research model was calculated using the equation:

$$
\mathrm{GoF}=\sqrt{\overline{\mathrm{AE}^{*}} \mathrm{R}^{-}}
$$

The calculated global goodness of fit $(\mathrm{GoF})$ is 0.43 , which exceed the threshold of $\mathrm{GoF}>0.36$ suggested by Wetzels, Odekerken-Schröder \& van Oppen (2009). Thus, this study concludes that the research model has a good overall fit.

\section{Discussion of Results}

The results in Table 4 and Figure 2 provide support for the three (3) hypotheses $(H 1, H 2$, and $H 3)$. Hypothesis 1 posited a positive relationship between service quality and customer satisfaction. Consistent with $\mathrm{H} 1$, the result in Table 4 and Figure 2, indicates that there is a significant $(t=3.477)$ positive $(\beta=0.452)$ relationship between service quality and customer satisfaction. Therefore, $\mathrm{H} 1$ is supported. Hypothesis 2 posited a positive association between service quality and customer trust. Hypothesis 2, results indicated that customer satisfaction is positively associated with customer trust $(\beta=0.391)$ and the relationship is significant ( $t=5.735)$. This is consistent with the prediction of $\mathrm{H} 2$ and is therefore supported. The standardized coefficient and significant levels of customer satisfaction $(\beta=0.324 ; t=4.429)$ is positive and 
significant. This is consistent with the prediction of $\mathrm{H} 3$ and is supported. Thus, a higher level of customer satisfaction is associated with higher levels of customer trust.

\subsection{Conclusion}

The purpose of this study was to investigate the influence of service quality on customer satisfaction and customer's trust. In particular, three hypotheses were postulated. To test the proposed hypotheses, data were collected from Gauteng Province in South Africa. The empirical result supported all the three posited research hypotheses in a significant way. Important to note about the study findings is the fact that service quality has influence on customer trust through customer satisfaction. This implies that service quality has stronger influence on customer trust when they first trigger the customer's satisfaction.

\subsection{Implications of the study}

While there is an increased recognition of customer trust as a critical aspect today's competitive business environment, the extant literature is replete with empirical evidence suggesting that service quality, and customer satisfaction are related constructs of customer trust. However, the current study was set to depart from this long held conventional wisdom and attempts to investigate the causal relationships between these constructs in service provision in the electricity industry. In particular, a successful attempt was made in this study to consider service quality and customer satisfaction as the predictors of customer trust. In addition to that, the current study investigate this contentious issues in an often most neglected research context - the African setting. Therefore, the findings of this empirical study are expected to provide fruitful new insights and implications to both academicians and electricity generation practitioners across the globe.

On the academic side, this study makes a significant contribution to the customer service and power generation literature by exploring the impact of service quality, and customer satisfaction on customer's trust in the context of South African - one of the newly developed countries on the African continent. In particular, the current study findings provide tentative support to the proposition that service quality and customer satisfaction should be recognized as antecedents and tools that precipitate customer trust in power generation industry.

On the practitioners' side, important influential role of service quality on customer's satisfaction and their trust to power generation brands in an African context are highlighted. Therefore, this study for instance submits that power generation operators seeking to find ways to develop and maintain customers trust should begin to consider this behaviour not only as the interplay of service quality and customer satisfaction but rather a behaviour that is precipitated by the quality of service provided, which then develops to customer satisfaction before it manifest itself in the form of trust with the service provider.

\subsection{Limitations and Future Research}

Although this study makes significant contributions to both academia and practice, it was limited in some ways, and therefore some future research avenues are suggested. First, the data were gathered from Gauteng Province of South Africa and the sample size of 151 is relatively small. Perhaps, the results would be more informative if the sample size is large and data gathered from the other eight provinces of the country are included. Therefore, future studies may be conducted by using data from other provinces in South Africa. Second, perhaps too, future studies should not be limited to South Africa, but rather consider extending this research to other African countries such as Zimbabwe for results comparison. Future studies can also extend the current study by studying the relationships in the current conceptual model in other sectors of the economy. Above and beyond, this will immensely contribute new knowledge to the existing body of consumer purchase behaviour in the power generation industry literature in the African setting - a research context which happens to be neglected in academics.

\section{References}

Andaleeb, S.S. 2001. Services quality perceptions and patient satisfaction: A study of hospitals in a developing country. Social Science and Medicine, 52:1359-1370.

Boshoff, C. \& du Plessis, F. 2009. Services Marketing: A Contemporary Approach. Juta and Company Ltd. Cape Town.

Brunner, T.A., Stocklin, M. \& Opwis, K. 2008. Satisfaction, Image, and Loyalty: New versus experienced customers. European Journal of 
Marketing, 42(9):1096-1105.

Calabresea, A. \& Scoglio, F. 2012. Reframing the past: A new approach in service quality assessment. Total Quality Management, 23 (11): 1329-1343.

Chen, S.C. 2012. The customer satisfaction relationship in an interactive e-service setting: The mediators. Journal of Retailing and Consumer Services, 19:202-210.

Chiu, S.I., Cheng, C.C., Yen, T.M. \& Hu, H.Y. 2011. Preliminary research in customer satisfaction models in Taiwan: A case study from the automobile industry. Expert Systems with Applications, 38:9780-9787.

Choi, K.S., Cho, W.H., Lee, S., Lee, H. \& Kim, C. 2004. The relationships among quality, value, satisfaction and behavioural intention in health care provider choice; A South Korean study. Journal of Business Research, 57:913-921.

Dado, J.; Petrovicova, T.; Cuzovic, S. \& Rajic, T. 2012. An Empirical examination of the relationships between service quality, satisfaction and behavioural intentions in higher education setting. Serbian Journal of Management, 7 (2):203- 218.

Dabholkar, P.A. \& Sheng, X. 2012. Consumer Participation in Using Online Recommendation Agents: Effects on Satisfaction, Trust, and Purchase Intentions. The Service Indusries Journal, 32(9):1433-1449.

Dos Santos, C.P. \& Fernandes, D.V.H. 2008. Antecedents and consequences of consumer trust in the context of service recovery. BAR, Curitiba, 5(3): 225-244.

Gill, A.S., Flaschner, A.B \& Shachar, M, 2006. Factors that affect the trust of business clients in their banks. International Journal of Bank Marketing, 24(6):384-405.

Hu, H.H.; Kandampully, J. \&Juwaheer, T.D. 2009. Relationships and impacts of service quality, perceived value, customer satisfaction, and image: An empirical study. The Service Industries Journal, 29(2): 111-125.

Irani, B., Fathollahzadeh, M. \& Alavi, M.A. 2012. Astudy of the determinants of customer revisit intentions: A case study in the branches of Sepah Bank in Ardabil province. Advances in Environmental Biology, 6(7):2026-2031.

Karjaluoto, H., Jayawardhena, C., Leppaniemi, M \& Pihlstrom, M. 2012. Telecommunications Policy, 36:636-649.

Liu, C.T, Guo, Y.M. \& Lee, C.H. (2011). The effects of relationship quality and switching barriers on customer loyalty. International Journal of Information Management, 31: 71-79

Naidu, A. 2009. Factors affecting patient and health care quality. International Journal of Health Care Quality Assurance, 22(4):366-381.

Olaru, D., \& Purchase, S. \& Peterson, N. 2008. From Customer Value to Repurchase Intentions and Recommendations. Journal of Business and Industrial Marketing, 23(8):558-565.

Ou, C.X. \&Sin, C.L. 2003.Customer Loyalty Strategy in the Internet Era. $7^{\text {th }}$ Pacific Asia Conference on Information Systems, 10-13 July, Adelaide, South Australia

Segoro, W. 2013. The influence of perceived services quality, mooring factor and relationship quality on customer satisfaction and loyalty. Pocedia-Social and Behavioural Sciences, 81:306-310.

Seto-Pamies, S. 2012. Customer loyalty to service providers: examining the role of service quality, customer satisfaction and trust. Total Quality Management, 23(11): 1257-1271.

Ting-Yueh Chang, T.Y. \&Horng, S.C. 2010. Conceptualizing and measuring experience quality: The customer's perspective. The Service Industries Journal, 30(14): 2401-2419.

Tseng, SM \& Huang, JS. (2011). The correlation between Wikipedia and knowledge sharing on job performance. Expert Systems with Applications, 38: 6118-6124

Appendix 1: Measurement Instruments

\section{System Performance}

This Eskom pre-paid system is efficient

This Eskom pre-paid system is effective

The Eskom pre-paid system solves my previous electricity billing problems

The Eskom pre-paid system helps me accomplish my tasks

This Eskom pre-paid system meets performance standards and expectations

\section{Customer Satisfaction}

I am satisfied with Eskom pre-paid system

I am satisfied with the relationship I have with Eskom Company

Overall I am satisfied with the service that I receive from Eskom pre-paid system

Trust

Eskom pre-paid system can be relied upon to keep promises

Eskom Company is trustworthy

I have full confidence in the Eskom pre-paid system 